Research Paper

\title{
Lacrimal Duct Occlusion Is Associated with Infectious Keratitis
}

\author{
Guigang $\mathrm{Li}^{1}$, Jingmin $\mathrm{Guo}^{1}$, Rong Liu${ }^{1}$, Weikun $\mathrm{Hu}^{1}$, Lingjuan $\mathrm{Xu}^{1}$, Juan Wang ${ }^{1}$, Subo Cai ${ }^{1}$, Hong Zhang1, \\ Yingting $\mathrm{Zhu}^{2 \bowtie}$ \\ 1. Department of Ophthalmology, Tongii Hospital, Tongji Medical College, Huazhong University of Science and Technology, Wuhan 430030, Hubei Province, \\ China \\ 2. TissueTech, Inc., Miami, FL, USA \\ \Corresponding author: yzhu@tissuetechinc.com
}

() Ivyspring International Publisher. Reproduction is permitted for personal, noncommercial use, provided that the article is in whole, unmodified, and properly cited. See http://ivyspring.com/terms for terms and conditions.

Received: 2016.06.17; Accepted: 2016.09.01; Published: 2016.10.17

\begin{abstract}
Background: To explore the prevalence of lacrimal duct obstruction in patients with infectious keratitis, and the necessity of lacrimal duct dredge in the treatment of human infectious keratitis.

Methodology/Principle Findings: The design is prospective, non-control case series. Thirty-one eyes from twenty-eight continuous patients with infectious keratitis were included in this study. The presence/absence of lacrimal duct obstruction was determined by the lacrimal duct irrigation test. The diagnosis of infectious keratitis was made based on clinical manifestations, cornea scraping microscopic examination and bacterial/fungus culture. Diagnosis of viral keratitis was set up based on the recurrent history, deep neovascularization and typical outlook of the cornea scar. The treatment of keratitis included drugs, eye drops or surgery, while treatment of chronic dacryocystitis was lacrimal duct dredging with supporting tube implantation surgery. In the thirty-one eyes with infectious keratitis, fifteen suffered from fungal keratitis (48\%), two bacterial keratitis $(6 \%)$, and fourteen viral keratitis (45\%). Eleven eyes (35\%) from ten patients with infectious keratitis also suffered from lacrimal duct obstruction. In those cases, six eyes also suffered from lower canalicular obstruction, three nasolacrimal duct obstruction and chronic dacryocystitis, one a combination of upper and lower canalicular obstruction, one upper canalicular obstruction. After local and systemic applications of anti-bacterial, anti-viral, anti-fungal and anti-inflammatory drugs, twenty-eight eyes $(90 \%)$ recovered within three weeks, while the ulceration of three patients required the lacrimal duct dredging and supporting tube implantation surgery for the healing.

Conclusions: Herein, we first report that the prevalence of infectious keratitis is closely correlated to the occurrence of lacrimal duct obstruction. When both confirmed, simultaneous treatment of keratitis and lacrimal duct obstruction promptly is required. Further evaluation of mechanism, prevention and control of the diseases are warranted.
\end{abstract}

Key words: Infectious Keratitis; Chronic Dacryocystitis; Lacrimal Duct Obstruction; Lacrimal Duct Dredging

\section{Introduction}

Infectious keratitis, an inflammation of the cornea caused by pathogens, is one of the major causes of monocular blindness, second only to that of cataract world widely [1-5]. It is also one of the most common medical challenges in the developing countries including China [6, 7]. The known pathogens of infectious keratitis are bacteria, fungus, virus, protozoa, and parasites (reviewed in [8]). In China, fungal keratitis is still one of major intractable diseases, composing an unusual high percentage of all types of keratitis due to severe lack of antifugal eye drops and poor knowledge of antifugal medicine, especially in the clinics of the vast rural areas [9]. The major risk factors for infectious keratitis include 
ocular trauma, contact lens wear, recent ocular surgery, preexisting ocular surface disease, dry eyes, lid deformity, corneal sensation impairment, chronic use of topical steroids and systemic immunosuppression [8, 10-15]. Although numerous studies on how to control and to treat this disease have been reported previously, the relationship between keratitis and the disorders of neighboring tissues/organs such as chronic dacryocystitis, an inflammatory disease of the lacrimal sac usually caused by lacrimal duct obstruction, has not been systematically explored previously.

Lacrimal drainage system consists of upper and lower lacrimal puncta, lacrimal canaliculi, common canaliculus, lacrimal sac and nasolacrimal duct, which drains tear fluid from the ocular surface into the nose (reviewed in [16]). Tear drainage system is extremely important for the maintenance of ocular surface health. For those with normal tear secretion, tear flow could brush away the harmful chemical and pathogens and keep the cornea from being infected. Unfortunately, the lacrimal duct canal is very tiny, with fine diameter in conjunction with some membrane, turns, and narrow points, which could not only prevent the tears from retro-flowing from the dirty nasal room (protective mechanism), but also could turn into occlusion that blocks the normal clearance of tears from the conjunctiva sac. As a result, obstruction of this drainage system can be congenital or acquired, which may cause persistent epiphora and mucopurulent discharge [17]. Consequently, occlusion of the lacrimal duct will eventually cause inflammation, and even worse, accumulation of the harmful materials and pathogens, such as fungus and bacteria, in the conjunctiva sac, raising the risk of cornea infection dramatically (reviewed in [17]). In the case of a prolonged infection of the lacrimal sac, secondary to obstruction of the nasolacrimal duct at the junction of lacrimal sac, chronic dacryocystitis is usually the outcome.

Though chronic dacryocystitis poses a potential threat to the intraocular infection which is usually taken as a contraindication for intraocular surgery, the important role of lacrimal duct system as a sweeper for the ocular surface has not been appropriately addressed in the studies of infectious keratitis. Importantly, when the lacrimal duct system is infected, the outflow of tear would be occluded, and the tear clearance be delayed. As a consequence, the imbalance of the normal flora of ocular surface would convert the ocular surface as a reservoir for corneal infection pathogens. Because the blindness may be caused by complication of keratitis and lacrimal duct obstruction, while the association between keratitis and lacrimal duct obstruction has not been addressed by scientific community, we have conducted this study to investigate the prevalence of lacrimal duct obstruction in patients suffering from infectious keratitis, and to evaluate the effectiveness of the treating infectious keratitis in conjunction with lacrimal duct dredging surgery in addition to drugs and cornea surgery, in order to reminder ophthalmologists and publics, for the first time, that the prevalence of infectious keratitis is highly associated with the occurrence of lacrimal duct obstruction, and the early diagnosis and treatment of lacrimal duct obstruction should also be made for the patients suffering from infectious keratitis.

\section{Methods}

A prospective non-control case study was conducted on 31 eyes (28 patients) with infectious keratitis in Tongi Hospital affiliated to Tongii Medical College, Huazhong University of Science and Technology, in which the patients were enrolled and followed consecutively from December 2012 to May 2013. The patients with Mooren's ulcer, marginal keratitis, interstitial keratitis and atheromatous ulcers were excluded from this study. This study was approved by the ethics committee of Tongji Hospital, Tongji Medical College, Huazhong University of Science and Technology, informed consent was obtained from each patient in accordance with the declaration of Helsinki.

Clinical diagnosis of infectious keratitis was set up based on detailed history (including recurrent or not), typical outlook of the corneal scars, deep neovascularization, slit-lamp microscopic examination, anterior segment Optical Coherence Tomography (as OCT), confocal microscopy, cornea scrape, microbiological examination (smears on the slides with $10 \% \mathrm{KOH}$ preparation), in conjunctions with confirmation of positive cultures for bacteria or fungi for final diagnosis of bacterial or fungal keratitis, or in conjunction with typical symptoms such as blurry vision, extreme photophobia, pain, redness, tearing, and presence of the multiple arborizing dendritic epithelial ulcers with terminal bulbs combined with positive response to antiviral Ganciclovir injection (intravenous injection, $0.5 \mathrm{~g}$ daily) for diagnosis of viral keratitis.

For the patients diagnosed of infectious keratitis, irrigation examination of lacrimal drainage system was performed immediately after the positive diagnosis and before any medical treatments, by surgeons who were masked from the patients' data. Lacrimal irrigation examination consisted of puncta dilation, lacrimal sac massage, and irrigation with saline to determine the point of obstruction. Drugs and eye drops treatment were given to patients 
according to their clinical and pathogenic diagnosis, cornea debridement, amniotic membrane transplantation or cornea transplantation. Surgery was performed when the infection could not be controlled by the medicine treatment. For treatment of chronic dacryocystitis, lacrimal duct dredging and supporting tube implantation surgery were also conducted after cornea debridement or transplantation surgery.

\section{Results}

The Patients A total of 28 patients (31 eyes) with infectious keratitis were included in this study. Thirteen patients in the left eyes (46\%), twelve patients in the right eyes (43\%), three patients $(11 \%)$ in both eyes. The ages ranged from 24 to 81 years old, averaged $55 \pm 15$. The patients included 16 males $(57 \%)$ and 12 females $(43 \%)$ (Table 1$)$.

For those ten patients with lacrimal duct obstruction or chronic dacryocystitis, seven occurred in the right eyes $(70 \%)$, two in the left $(20 \%)$ and one in both eyes (10\%), including 6 males and 4 females. The average age was $(59 \pm 14)$ years old (Table 2$)$.

Table 1. General Information of 28 Patients (31Eyes) with Infectious Keratitis

\begin{tabular}{llllllll}
\hline & Patients & Right & Left & Both & Age & Male & Female \\
& $\mathbf{N}$ & $\mathbf{N}(\%)$ & $\mathbf{N}(\%)$ & N (\%) & (SD) & N (\%) & N (\%) \\
\hline Fungal & 14 & 6 & 8 & 0 & & 10 & 4 \\
Viral & 12 & 6 & 3 & 3 & & 5 & 7 \\
Bacterial & 2 & 0 & 2 & 0 & & 1 & 1 \\
Total & 28 & $12(43 \%)$ & $13(46 \%)$ & $3(11 \%)$ & $55(15)$ & $16(57 \%)$ & $12(43 \%)$
\end{tabular}

Table 2. General Information of 10 Patients (1leyes) with Lacrimal Duct Obstruction

\begin{tabular}{llllllll}
\hline & $\begin{array}{l}\text { Patients Right } \\
\mathbf{N}(\%)\end{array}$ & $\begin{array}{l}\text { Left } \\
\mathbf{N}(\%)\end{array}$ & $\begin{array}{l}\text { Both } \\
\mathbf{N}(\%)\end{array}$ & $\begin{array}{l}\text { Age } \\
\text { (SD) }\end{array}$ & $\begin{array}{l}\text { Male } \\
\mathbf{N}(\%)\end{array}$ & $\begin{array}{l}\text { Female } \\
\mathbf{N}(\%)\end{array}$ \\
\hline Fungal & 3 & 2 & 1 & & & 2 & 1 \\
Viral & 6 & 5 & & 1 & 3 & 3 \\
Bacterial & 1 & 0 & 1 & & & 1 & 0 \\
Total & 10 & $7(70 \%)$ & $2(20 \%)$ & $1(10 \%)$ & $59(14)$ & $6(60 \%)$ & $4(40 \%)$ \\
\hline
\end{tabular}

The Pathogens Of the 31 eyes, fourteen had fungal infections (45\%), two bacterial infections (6\%), and fifteen virus infections (48\%).

The Medicine Treatment After diagnosis of infectious keratitis and lacrimal duct obstruction, patients were initially treated with topical broad-spectrum antibiotics in prevision of bacterial infection. For fungal keratis, antifungal agents Fluconazole injection (Pfizer Inc. USA) was used systematically, intravenously at a dose of $0.2 \mathrm{~g}$ daily. $5 \%$ Natamycin (Alcon, USA), 0.25\% Amphotericin B (Huabei Pharmaceutical Group, China) and 0.2\%
Fluconazole (Pfizer Inc. USA) were administered topically, as eye drops used every two hours. Non-steroidal anti-inflammatory drug $0.1 \%$ Pranoprofen Drops (Qianshou Pharmaceutical Co., Ltd. of Japan) was used four times per day. Antifungal medications were administered continuously before and after surgery. The frequency of antifungal therapy was maintained or tapered according to the clinical situations as previously reported [18]. For bacterial keratitis, antibiotics Cefamandole Nafate for Injection (Hebei Huamin Pharmaceutical Co., Ltd. China) was used systemically, intravenously at a dose of $3 \mathrm{~g}$ daily, $0.5 \%$ Levofloxacin was administered topically as eye drops every two hours. For viral keratitis, antiviral Ganciclovir injection (introvenous injection, $0.5 \mathrm{~g}$ daily) (Shanghai Roche Pharmaceuticals, China) in conjunction with eye drops.

The Association Based on the results of lacrimal duct irrigation, totally eleven eyes were also diagnosed as lacrimal duct obstruction (35\%, Table 3$)$.

Table 3. Characteristic of Lacrimal Duct Obstruction in 10 Patients (11 Eyes)

\begin{tabular}{|c|c|c|c|c|c|}
\hline & Sex & Age & Onset Time & Eye & $\begin{array}{l}\text { Lacrimal duct obstruction } \\
\text { points }\end{array}$ \\
\hline \multirow[t]{3}{*}{ Fungal } & F & 52 & 2 weeks & OS & Nasolacrimal duct obstruction \\
\hline & M & 67 & 2 months & OS & Lower canalicular obstruction \\
\hline & $\mathrm{F}$ & 72 & 2 weeks & OS & Nasolacrimal duct obstruction \\
\hline \multirow[t]{7}{*}{ Viral } & M & 29 & 24 years & OD & Lower canalicular obstruction \\
\hline & M & 59 & 25 years & OD & Lower canalicular obstruction \\
\hline & $\mathrm{F}$ & 55 & 20 days & $\mathrm{OU}$ & Lower canalicular obstruction \\
\hline & $\mathrm{F}$ & 51 & 11 days & OD & $\begin{array}{l}\text { Upper and lowercanalicular } \\
\text { obstruction }\end{array}$ \\
\hline & M & 60 & 2 months & OD & Upper canalicularobstruction \\
\hline & & & & OS & Lower canalicular obstruction \\
\hline & M & 68 & 2 months & OD & $\begin{array}{l}\text { Lowerpuncta and } \\
\text { canalicularobstruction }\end{array}$ \\
\hline Bacterial & M & 81 & 1 weeks & OS & Nasolacrimal duct obstruction \\
\hline
\end{tabular}

F-female, M-male, OD-right eye, OS-left eyes, OU-both eyes.

Among the 11 cases, seven was complicated with viral keratitis, three with fungal keratitis and one with bacterial keratitis. The obstruction points of the lacrimal duct could be further divided into lower puncta and canalicular obstruction (6/11 cases), nasolacrimal duct obstruction (3/11 cases), both upper and lower canalicular obstruction (1/11 cases), upper canalicular obstruction (1/11 cases). All three eyes with nasolacrimal duct obstruction were also diagnosed as chronic dacryocystitis based on the symptoms of persistent epiphora and mucopurulent discharge.

The Outcome After medical treatment and cornea surgery, including cornea debridement or transplantation surgery, infection was controlled and cornea epithelium healed within one to three weeks in 
twenty-eight eyes (90\%). For those three cases of patients suffering from chronic dacryocystitis complicated with fungal keratitis (two cases, Figure 1, 2) and bacterial keratitis (one case, Figure 3), the ulceration was progressed in the first week. However, the infection was controlled and cornea epithelium healed only after lacrimal duct dredging surgery was performed (Table 4, Figure 1-3).

Table 4. Treatment Profiles for Three Patients with Chronic Dacryocystitis

\begin{tabular}{|c|c|c|c|c|}
\hline & Pathogen & $\begin{array}{l}\text { Cornea } \\
\text { surgery }\end{array}$ & Lacrimal Duct surgery & $\begin{array}{l}\text { Healing } \\
\text { time }\end{array}$ \\
\hline Cases 1 & Fusarium & PKP & Lacrimal duct & 4 weeks \\
\hline Cases 2 & Aspergillusflavus & PKP & Dredge and Supporting & 2 weeks \\
\hline Cases 3 & $\begin{array}{l}\text { Pseudomonas } \\
\text { Aeruginosa }\end{array}$ & PKP & $\begin{array}{l}\text { tube } \\
\text { Implantation Surgery }\end{array}$ & 2 weeks \\
\hline
\end{tabular}
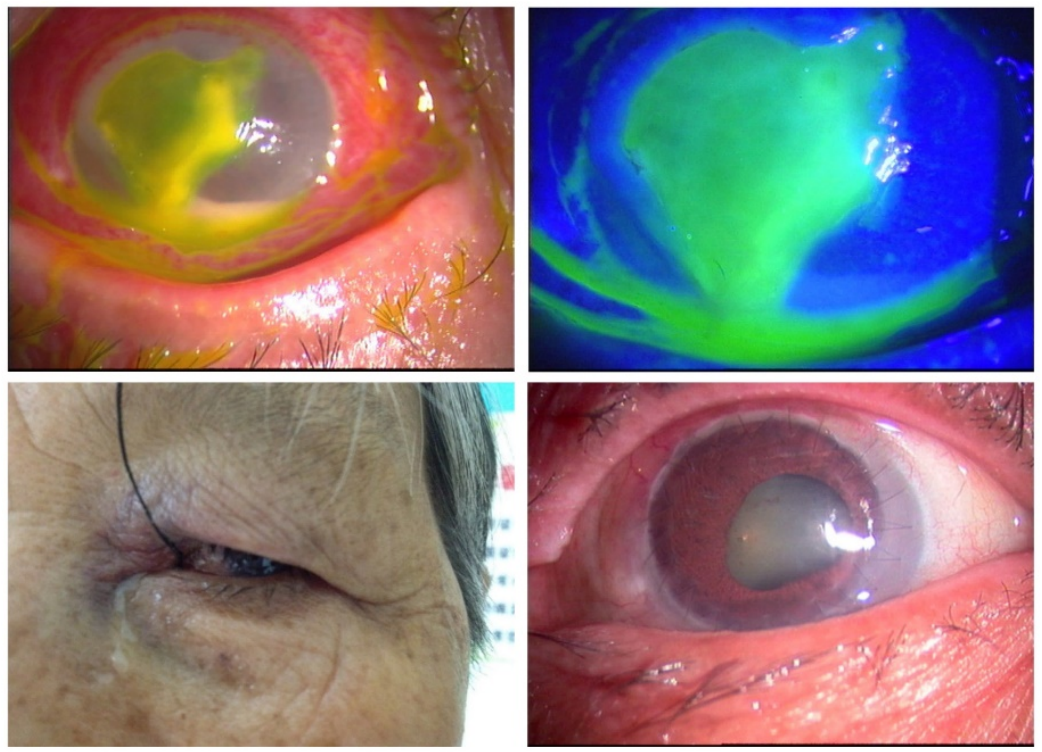

Figure 1. Observation for Case 1 Patient with Chronic Dacryocystitis and Nasolacrimal Duct Obstruction. Case 1, female, 52 years old, left eye red and pain after rice leaf injury, tearing, reduced visual sight for two weeks. Examined under slit lamp microscope, with irregular ulceration of $7 * 9 \mathrm{~mm}$, deep stroma Infiltration and hypopyon (top left), sodium fluorescein staining showed tears accumulated in the conjunctival sac because of nasolacrimal duct obstruction and chronic dacryocystitis, which could be identified through lacrimal duct irrigation test (top right). Lacrimal duct dredge and support tube implantation surgery was performed one week after allogenic penetrating keratoplasty (bottom left). Four weeks later, infection was controlled and epithelial healed (bottom right). Culture of the cornea scrape material showed Fusarium fungus growth.
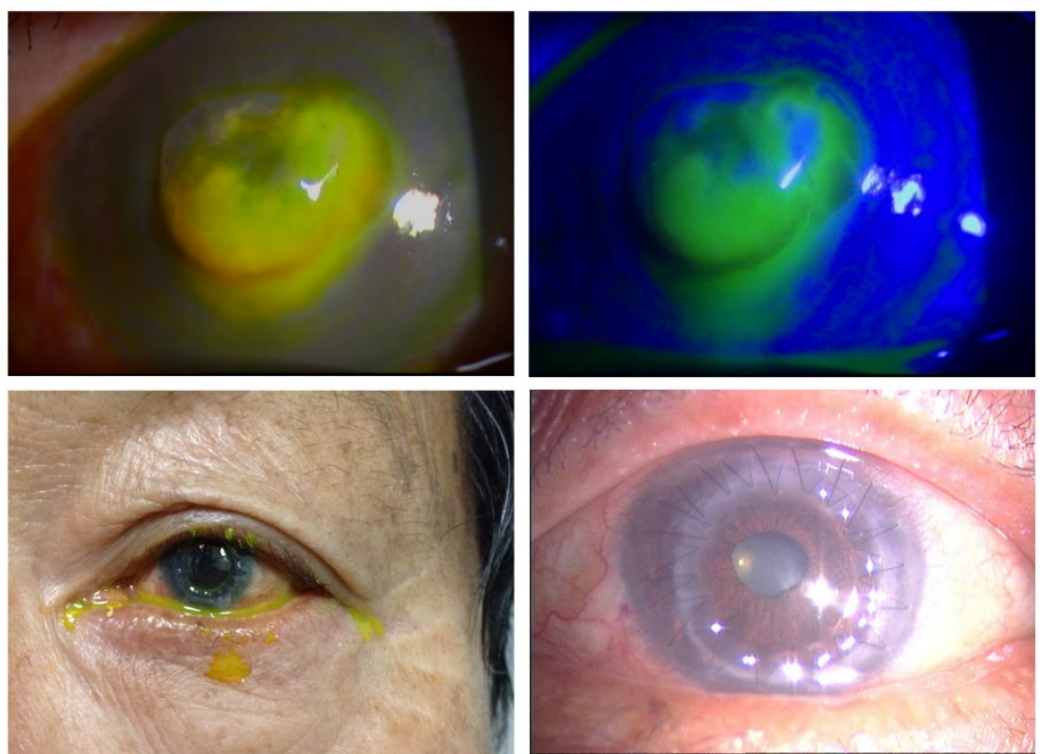

Figure 2. Observation for Case 2 Patient with Chronic Dacryocystitis and Nasolacrimal Duct Obstruction. Case 2, female, 72 years old, left eye red and pain after rice leaf injury, tearing, reduced visual sight for two weeks. Examined under slit lamp microscope, with irregular ulceration of $5 * 6 \mathrm{~mm}$, central corneal perforation ectasia (top left), sodium fluorescein staining showed tears accumulated in the conjunctival sac because of nasolacrimal duct obstruction and chronic dacryocystitis, which could be identified through lacrimal duct irrigation test (top right and bottom left). Infection was controlled and epithelium healed 2 weeks after allogenic penetrating keratoplasty and lacrimal duct dredge and support tube implantation surgery (bottom right). Culture of the cornea scrape material showed Aspergillusflavus growth. 

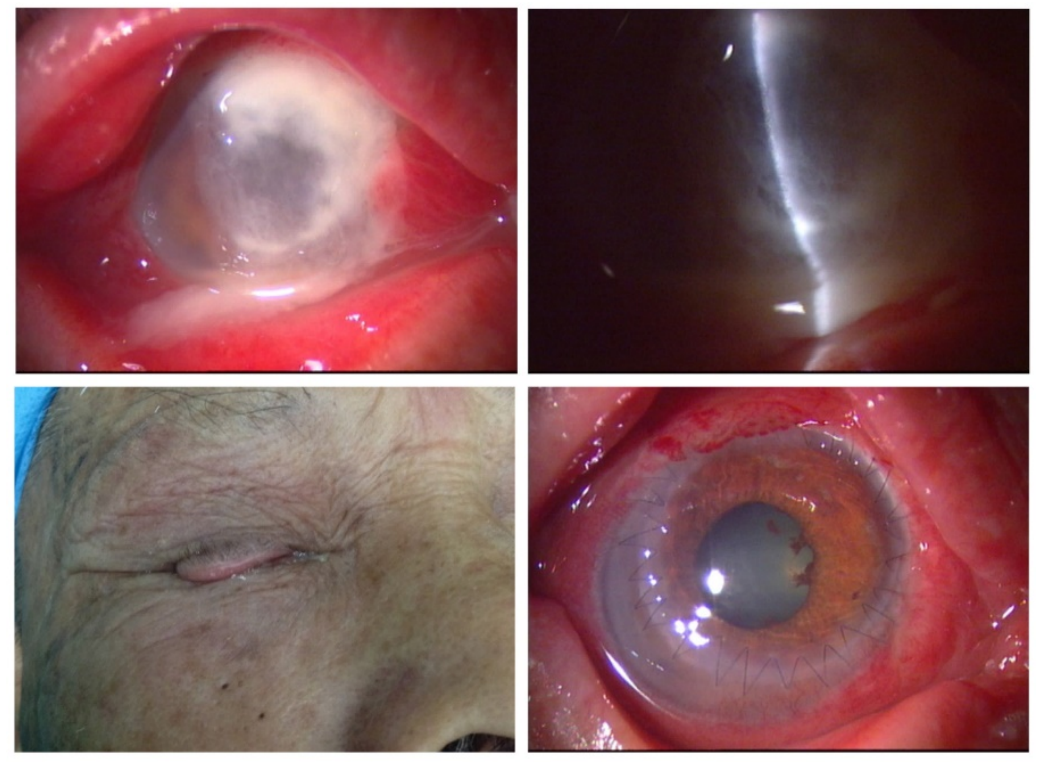

Figure 3. Observation for Case 3 Patient with Chronic Dacryocystitis and Nasolacrimal Duct Obstruction. Case 3, male, 81 years old, right eye red and pain after uncertain cornea trauma, tearing, reduced visual sight for one week. Examined under slit lamp microscope, with irregular ulceration of $7 * 8 \mathrm{~mm}$, central Corneal melting and thin Purulent secretions (top left and top right), tears accumulated in the conjunctival sac because nasolacrimal duct obstruction and chronic dacryocystitis, which could be identified through lacrimal duct irrigation test (bottom left). Infection was controlled and epithelial healed 2 weeks after allogenic penetrating keratoplasty and lacrimal duct dredge and support tube implantation surgery (bottom right). Culture of the cornea scrape materials showed pseudomonas aeruginosa growth.

\section{Discussion}

Although it is well known that there are plenty of fungi and bacteria in the conjunctiva sac of normal population [19. 20], we cannot image that the prevalence of fungi and bacteria are dramatically higher in the conjunctiva sac of patients with the lacrimal duct occlusion disease than that of normal population [21]. Because no published records suggest there is a possible link between infectious keratitis and lacrimal duct occlusion, and no published data delineate whether such high ration of pathogens in lacrimal duct occlusion would eventually elevate the risk of infectious keratitis, and if so, how important it is to diagnose and to treat chronic dacryocystitis in conjunction with the treatment of serious infectious kertitis, we have therefore conducted this prospective study. Alarmingly, our data show that $35 \%$ of the eyes with infectious keratitis also suffered with different kinds of lacrimal duct system abnormality, including chronic dacryocystitis. Such prevalence is obviously higher than that of the normal people because in one population-based study, Woog MD reported the average annual incidence rate of lacrimal duct system disease above the age of 5 years was $0.03 \%$ [22], suggesting that patients with infectious keratitis have significantly higher prevalence of lacrimal duct obstruction than those in the general healthy population. More importantly, patients in our study had no history of lacrimal duct obstruction previously, that is, they were diagnosed as lacrimal duct obstruction for the first time only after their infectious keratitis were so serious that they had to be treated in the inpatients' ward.

One of the most important questions is how does this change contribute to the outcome of keratitis? The ocular surface of healthy individuals normally has a microbial flora, most commonly, a small population of bacteria typically coagulase-negative staphylococci $[23,24]$. Under normal conditions, this microbial flora may help to exclude harmful pathogens, maintain the immune response to the injury, and make the ocular surface a peaceful ecosystem [23]. However, when this balance is broken, the normal microbial flora would change. As a result, an infection would occur. For example, lacrimal duct obstruction might destroy the tear film dynamics, delay microbial clearance, change the normal microbial flora on the surface and make cornea liable to infection by both Grampositive and Gram negative organisms. Typically, Staphylococci are associated with chronic dacryocystitis [25, 26]. Similarly, Fungi have been found to be related with chronic dacryocystitis in China [25]. Because Banerjee $S$ et al have reported that Chronic conjunctivitis due to lacrimal system blockage can be relieved by dacryocystorhinostomy [27], we have proposed that a proper diagnose and treatment of lacrimal duct obstruction should be considered in the management of infectious keratitis. In consistent to the previous study, the most common obstruction points in our study was lower canalicular [28]. The high risk of lower canalicular occlusion could be secondary to keratitis because ocular 
inflammation and toxic effects of topical medicines might increase predisposition to lower canalicular obstruction [28]. We have also noted that Fluconazole injection in conjunction with Natamycin, Amphotericin B and Fluconazole was effective for fungal keratis, Cefamandole Nafate effective for bacterial keratitis, and antiviral Ganciclovir injection effective for viral keratitis. In all, after medical treatment and cornea surgery, infection was controlled and cornea epithelium healed within one to three weeks in twenty-eight eyes (approximately $90 \%$ ). For those three cases of patients also had chronic dacryocystitis, the infection was not controlled and cornea epithelium healed only after lacrimal duct dredging surgery were performed (Table 4, Figure 1-3).

In summary, our research reveals for the first time that infectious keratitis is in highly correlation to lacrimal duct obstruction (approximately 35\%), to best of our knowledge. On one hand, lacrimal duct obstruction may delay tear film clearance, change the normal microbial flora and make cornea liable to the infection. On the other hand, infectious keratitis may promote the obstruction of lacrimal duct especially lower canalicular obstruction. Thus it is important to make an early diagnosis of lacrimal duct obstruction for cornea infection control. It is equally important to treat infectious keratitis via appropriate drugs as early as possible and cornea surgery when needed.

\section{Acknowledgements}

Funding: This project has been supported by the National Natural Science Foundation of China (Grant No. 81200661, 81470606), the Nature Science Foundation of Hubei Province, China (Grant No. 2014CFB973).

Contribution: Guigang Li contributes to prepare specific aims, experimental design, experiments, manuscript; Jingmin Guo contributes to prepare experimental design and experiments; Rong Liu contributes to prepare experimental design, and experiments; Weikun $\mathrm{Hu}$ contributes to prepare experiments; Lingjuan $\mathrm{Xu}$ contributes to prepare experiments; Juan Wang contributes to prepare experiments; Subo Cai contributes to prepare experiments; Hong Zhang contributes to prepare experiments; Yingting Zhu contributes to prepare specific aims, experimental design and manuscript.

\section{Competing Interests}

The authors have declared that no competing interest exists.

\section{References}

1. McLeod SD, LaBree LD, Tayyanipour R, Flower CW, Lee PP et al. The importance of initial management in the treatment of severe infectious corneal ulcers. Ophthalmology 1995;102:1943-8.

2. Wong T, Ormonde S, Gamble G, McGhee CN. Severe infective keratitis leading to hospital admission in New Zealand. Br.J.Ophthalmol. 2003;87:1103-8.

3. Bourcier T, Thomas F, Borderie V, Chaumeil C, Laroche L. Bacterial keratitis: predisposing factors, clinical and microbiological review of 300 cases. Br.J.Ophthalmol. 2003;87:834-8.

4. Keay L, Edwards K, Naduvilath T, Taylor HR, Snibson GR et al. Microbial keratitis predisposing factors and morbidity. Ophthalmology 2006;113:109-16.

5. Ibrahim YW, Boase DL, Cree IA. Epidemiological characteristics, predisposing factors and microbiological profiles of infectious corneal ulcers: the Portsmouth corneal ulcer study. Br.J.Ophthalmol. 2009;93:1319-24.

6. Liang YB, Friedman DS, Wong TY, Zhan SY, Sun LP et al. Prevalence and causes of low vision and blindness in a rural chinese adult population: the Handan Eye Study. Ophthalmology 2008;115:1965-72.

7. Whitcher JP, Srinivasan M, Upadhyay MP. Corneal blindness: a global perspective. Bull.World Health Organ 2001;79:214-21.

8. Alio JL, Abbouda A, Valle DD, Del Castillo JM, Fernandez JA. Corneal cross linking and infectious keratitis: a systematic review with a meta-analysis of reported cases. J.Ophthalmic Inflamm.Infect. 2013;3:47.

9. Shi WY, Wang T. [Several problems of diagnosis and treatment in fungal keratitis in China]. Zhonghua Yan.Ke.Za Zhi. 2013;49:2-5.

10. Jeng BH, Gritz DC, Kumar AB, Holsclaw DS, Porco TC et al. Epidemiology of ulcerative keratitis in Northern California. Arch.Ophthalmol. 2010;128:1022-8.

11. Saeed A, D'Arcy F, Stack J, Collum LM, Power W et al. Risk factors, microbiological findings, and clinical outcomes in cases of microbial keratitis admitted to a tertiary referral center in ireland. Cornea 2009;28:285-92.

12. Green M, Apel A, Stapleton F. Risk factors and causative organisms in microbial keratitis. Cornea 2008;27:22-7.

13. Narayanan S, Redfern RL, Miller WL, Nichols KK, McDermott AM. Dry eye disease and microbial keratitis: is there a connection? Ocul.Surf. 2013;11:75-92.

14. Amescua G, Miller D, Alfonso EC. What is causing the corneal ulcer? Management strategies for unresponsive corneal ulceration. Eye (Lond) 2012;26:228-36.

15. Passos RM, Cariello AJ, Yu MC, Hofling-Lima AL. Microbial keratitis in the elderly: a 32-year review. Arq Bras.Oftalmol. 2010;73:315-9.

16. Kashkouli MB, Pakdel F, Kiavash V. Assessment and management of proximal and incomplete symptomatic obstruction of the lacrimal drainage system. Middle East Afr.J.Ophthalmol. 2012;19:60-9.

17. Mandeville JT, Woog JJ. Obstruction of the lacrimal drainage system. Curr.Opin.Ophthalmol. 2002;13:303-9.

18. Zeng B, Wang P, Xu LJ, Li XY, Zhang $\mathrm{H}$ et al. Amniotic membrane covering promotes healing of cornea epithelium and improves visual acuity after debridement for fungal keratitis. Int.J.Ophthalmol. 2014;7:785-9.

19. Graham JE, Moore JE, Jiru X, Moore JE, Goodall EA et al. Ocular pathogen or commensal: a PCR-based study of surface bacterial flora in normal and dry eyes. Invest Ophthalmol.Vis.Sci. 2007;48:5616-23.

20. Xuguang S, Zhixin W, Zhiqun W, Shiyun L, Ran L. Ocular fungal isolates and antifungal susceptibility in northern China. Am.J.Ophthalmol. 2007;143:131-3.

21. Shah CP, Santani D. A comparative bacteriological profile and antibiogram of dacryocystitis. Nepal.J.Ophthalmol. 2011;3:134-9.

22. Woog JJ. The incidence of symptomatic acquired lacrimal outflow obstruction among residents of Olmsted County, Minnesota, 1976-2000 (an American Ophthalmological Society thesis). Trans.Am.Ophthalmol.Soc. 2007;105:649-66.

23. Miller D, Iovieno A. The role of microbial flora on the ocular surface. Curr.Opin.Allergy Clin.Immunol. 2009;9:466-70.

24. Capriotti JA, Pelletier JS, Shah M, Caivano DM, Ritterband DC. Normal ocular flora in healthy eyes from a rural population in Sierra Leone. Int.Ophthalmol. 2009;29:81-4.

25. Sun X, Liang Q, Luo S, Wang Z, Li R et al. Microbiological analysis of chronic dacryocystitis. Ophthalmic Physiol Opt. 2005;25:261-3.

26. Razavi ME, nsari-Astaneh MR, Farzadnia M, Rahmaniyan H, Moghiman T. Bacteriological evaluation of adult dacryocystitis in Iran. Orbit. 2010;29:286-90.

27. Banerjee S, McDonnell PJ. Chronic conjunctivitis due to lacrimal system blockage relieved by dacryocystorhinostomy. Eye (Lond) 2000;14(Pt 5):792-3.

28. Warren JF, Seiff SR, Kavanagh MC. Long-term results of external dacryocystorhinostomy. Ophthalmic Surg.Lasers Imaging 2005;36:446-50. 